\title{
Can Brands Claim Ignorance? Unauthorized Subcontracting in Apparel Supply Chains
}

\author{
Felipe Caro \\ UCLA Anderson School of Management, Los Angeles, CA 90095, fcaro@anderson.ucla.edu \\ Leonard Lane \\ UCI Paul Merage School of Business, Irvine, CA 92697, llane@uci.edu
}

Anna Sáez de Tejada Cuenca

IESE Business School, University of Navarra, 08034 Barcelona, Spain, asaezdetejada@iese.edu

\begin{abstract}
Unauthorized subcontracting - when suppliers outsource part of their production to a third party without the retailer's consent - has been common practice in the apparel industry and is often tied to non-compliant working conditions. Because retailers are unaware of the third party, the production process becomes obscure and cannot be tracked. In this paper we present an empirical study of the factors that can lead suppliers to engage in unauthorized subcontracting. We use data provided by a global supply chain manager with over 30,000 orders, of which $36 \%$ were subcontracted without authorization. We find that the frequency of unauthorized subcontracting across factories has a pronounced bimodal distribution. Moreover, the degree of unauthorized subcontracting in the past is highly related to the probability of engaging in unauthorized subcontracting in the future, which suggests that factories behave as if they choose a strategic level of unauthorized subcontracting. At the order level, we find that state dependence (i.e., the status of an order carrying over to the next one) and price pressure are the key drivers of unauthorized subcontracting. Buyer reputation and lead time also play a role. Finally, we show that unauthorized subcontracting can be predicted correctly for more than $80 \%$ of the orders in out-of-sample tests, and for about $70 \%$ of suppliers. This indicates that retailers can use business analytics to predict unauthorized subcontracting and help prevent it.
\end{abstract}

Key words: unauthorized subcontracting; social responsibility; compliance; sustainability; supply chain management; empirical operations management

History: This paper was first submitted on December 14, 2016.

\section{Introduction}

"Lack of transparency costs lives. It is impossible for companies to make sure human rights are respected and that environmental practices are sound without knowing where their products are made, who is making them and under what conditions. If you can't see it, you don't know it's going on and you can't fix it." (Moore et al. 2016) 
The Rana Plaza collapse in Bangladesh in April 2013, which killed 1,129 people, revealed to the international community the non-compliant working conditions of many apparel workers in developing countries. The major brands that had ongoing production at the Rana Plaza claimed that they had not placed their orders to any of those factories (Kerppola et al. 2014). This was not an isolated event. A few months earlier, a fire in the Tazreen Fashion factory on the outskirts of Dhaka, Bangladesh, killed more than 100 workers. Products for a large U.S. retailer were found at the Tarzeen facility, and though these garments were part of an order that had been placed at an authorized factory, they ended up at the location of the fire due to unauthorized subcontracting (Donaldson 2015). Over a decade, more than 1,800 apparel workers in Bangladesh died due to workplace disasters, mostly at unauthorized factories (Clifford and Greenhouse 2013). Despite multiple efforts launched following these disasters, the intricate network of unauthorized subcontractors continues to exist (Drennan 2015). This is concerning for supply chains because of the risk that the subcontractors might be non-compliant.

The lack of visibility from unauthorized subcontracting allows for obscure practices, especially non-compliant working conditions. These practices have been endemic to the apparel industry in developing countries for decades. The issue received worldwide attention with the incidents in Bangladesh. However, many other incidents - possibly smaller in magnitude but no less gravehave been reported in almost every developing country where apparel manufacturing takes place. For instance, in China there was a recent case of a factory that diverted production of a major Australian brand to a facility in North Korea where forced labor was employed (McKenzie and Baker 2016). In Vietnam, a flurry of garments destined for suppliers of multinational companies were being produced under degrading conditions in detention centers (Theuws 2015). In Cambodia, a factory with unsafe working conditions was in the spotlight but the brands linked to the factory dodged the blame saying that the orders had been rerouted without their permission (Robertson and Heng 2014). These examples are limited to the cases that have been caught by the press. The actual number of incidents is likely to be much larger.

Although most companies are already actively involved in improving suppliers' working conditions through codes of conduct, auditing, adherence to domestic and international regulations, etc., the complex nature of supply chains in the apparel industry makes it very difficult for retailers to track where their products are actually manufactured. Often a supplier subcontracts an order to a non-compliant third party without the buyer's authorization or even knowledge (Donaldson 2017). As a consequence, despite the multiple efforts from retailers, many violations of building codes and labor standards remain unnoticed by the retailers. Of course, it is possible that a supplier subcontracts an order to another factory that happens to be compliant. However, once an order has been subcontracted without authorization, the buyer loses visibility and it is impossible to monitor the 
Caro, Lane, and Sáez de Tejada Cuenca: Can Brands Claim Ignorance?

actual conditions in which the order has been produced. For this reason, knowing where clothes are being made has become an industry imperative (Moore et al. 2016).

In this paper, we propose two research questions. First, what are the main drivers of unauthorized subcontracting? Second, can brands claim ignorance? In other words, when unauthorized subcontracting takes place, could retailers have anticipated it and, therefore, prevented it?

To find a response to the first question, we run an empirical study to analyze the variables that are correlated with unauthorized subcontracting using data from a middleman that matches retailers with suppliers in several developing countries. The data spans eight months in 2013-14 and consists of over 32,000 orders from 226 factories delivered to 30 buyers. Unauthorized subcontracting is reported in $36.4 \%$ of the orders in our sample. However, we find that there are big differences among factories. We observe three consistent patterns. For some factories, there is no incidence of unauthorized subcontracting; for others, it occurs in 100\% of the orders; and, for a third group of factories, it happens occasionally. Most importantly, the propensity of each firm to engage in unauthorized subcontracting emerges as an inherent characteristic or strategic choice that can be (partially) inferred from past behavior.

We argue that factories' unauthorized subcontracting behavior exhibits state dependence (Heckman 1981, Wooldridge 2010). That is, a factory that just delivered an order that was subcontracted without authorization is more likely to do the same for the next order. We validate this hypothesis by testing whether unauthorized subcontracting is autoregressive. The result is large in magnitude and is statistically significant. We find that the probability of unauthorized subcontracting increases by $87 \%$, i.e., almost doubles, when the previous order at the same factory was also subcontracted without authorization. Based on the extant literature, we analyze four additional order-level characteristics that could drive unauthorized subcontracting. First, we find that price pressure (i.e., when the unit price of an order is below the historic baseline for a given category and factory) is positively correlated with the probability of unauthorized subcontracting. For instance, when the price is $25 \%$ lower than usual, the likelihood of unauthorized subcontracting increases by $9 \%$. Second, when the final buyer is a well-known brand, the probability of unauthorized subcontracting is $22 \%$ lower. Third, orders with longer lead times - which is most common for basic products as opposed to fashion items - are more likely to be subcontracted to unauthorized suppliers. We find no evidence that more complex orders are more likely to be subcontracted. Our empirical approach considers instrumental variables for state dependence, price, and lead time. Note that our data was collected shortly after the Rana Plaza collapse, which increased the worldwide scrutiny on unauthorized subcontracting. Therefore, our estimates are arguably conservative compared to a business-as-usual scenario. 
For the second research question we use a simple linear prediction model to detect unauthorized subcontracting at the order level. The model leverages our findings on the drivers of unauthorized subcontracting. Therefore, it includes a factory (fixed) effect and order characteristics, such as price pressure. We partition the data into training and testing subsamples and we find that more than $82 \%$ of the test orders can be correctly predicted using the model calibrated with the training dataset. Depending on data availability, the prediction accuracy can be above $90 \%$. Moreover, the proportion of false positives (type I errors) and false negatives (type II errors) in the outof-sample tests are well balanced. We also use a linear prediction model at the supplier level to predict whether or not a supplier for whom we have no past subcontracting data will engage in this behavior in the future. Our model has an accuracy between $63 \%$ and $80 \%$. These results are robust to the training and testing data split, which indicates that, to a great extent, unauthorized subcontracting is predictable, and therefore can be managed.

Our work contributes to the literature on supplier compliance and supply chain visibility. The goal of the study is not to incite finger-pointing between brands and suppliers but rather demonstrate that the use of data and models can help in addressing the issue of unauthorized subcontracting. For instance, some variation of our models can be embedded in a decision support system to help inform the decision on where to place orders or what suppliers to work with. Our results also show the need for more collaboration between buyers and suppliers. Though price is always important, we find that working closely with the supplier to avoid situations (or states) that push the factory into unauthorized subcontracting can also be effective. For instance, coordinated planning and scheduling can prevent periods of excessive workload. Implementing measures to reduce unauthorized subcontracting can help buyers reduce compliance risk and increase supply chain visibility.

In this paper, "subcontracting" will be used as a synonym of "unauthorized subcontracting" unless explicitly stated that it is authorized. In addition, "supplier" and "factory" will be used interchangeably as all of the factories in our data belong to different firms (suppliers).

\section{Literature Review}

Unauthorized subcontracting, before the Rana Plaza collapse, did not receive much attention in the academic literature. However, two streams of literature are closely related to this topic: first, papers related to compliance with environmental and labor standards; second, papers related to supply chain design.

What determines factories' compliance levels? Some of the factors listed in the literature are policy-related and thus external to suppliers. For example, differences between countries, related to differences in regulations and enforcement (M. Taplin 2014), and inspections and freedom of press 
Caro, Lane, and Sáez de Tejada Cuenca: Can Brands Claim Ignorance?

Article submitted to Management Science; manuscript no. MS-16-02459.R2

(Toffel et al. 2015). In China, severe price pressure from Western buyers, short-term opportunism, lack of observability, and corruption and passiveness in the government are factors that induce suppliers to adulterate their products (Tang and Babich 2014). In addition to the social characteristics of the supplier's location and regulation levels, compliance levels are also a consequence of buyers' purchasing practices, such as pressure to deliver high-quality products at increasingly short lead times and low prices (Barrientos and Smith 2007, Locke et al. 2009, Jiang 2009, Anner et al. 2013, M. Taplin 2014, Anner 2018, 2019), the characteristics of supplier-buyer relationships such as the length of their contract and their degree of involvement (Barrientos and Smith 2007, Jiang 2009, Locke et al. 2007), and strategic decisions such as the adoption of lean manufacturing standards (Distelhorst et al. 2016). The relationship between buyers' sourcing practices and compliance is well-studied in field surveys from NGOs and other non-academic institutions (Ashida and Plinke 2004, Labowitz and Baumann-Pauly 2014, 2015, Vaughan-Whitehead and Pinedo Caro 2017). We study unauthorized subcontracting as a special case of compliance, and focus mainly on its operational drivers. However, as opposed to the previous literature, which focuses on suppliers' compliance levels with relation to general lead time and price trends, we study unauthorized subcontracting at the order level and observe how subcontracting decisions change under different order characteristics.

A large part of the literature on compliance is focused on inspections and audits. Inspections can decrease the incentive for the supplier to adulterate products (Babich and Tang 2012). However, they can also be counterproductive since they can incentivize suppliers to decrease transparency (Locke et al. 2007). In some circumstances, scheduled inspections are more efficient than random ones as an incentive for the firm to disclose environmental violations (Kim 2015). Among the papers on the effect of inspections in compliance, one is particularly related to our work: Plambeck and Taylor (2016), who analyze the effects of audits on compliance with labor and environmental standards, and on unauthorized subcontracting. They show that the potential for a supplier to pass an audit through hiding reduces the optimal level of auditing for the buyer when either the margin or the buyer's damage for sourcing with violations is small. Their results hold for the case of unauthorized subcontracting: when the supplier will likely be able to hide its subcontracting behavior, more auditing from the buyer can backfire and cause the supplier to exert more effort in hiding its subcontracting practices than in avoiding unauthorized subcontracting altogether.

Incentives and penalties to increase environmental and social compliance have been studied extensively. Incentives have a higher effect than penalties in violation reduction (Porteous et al. 2015). Some mechanisms that can prevent suppliers from adulterating their products, in addition to inspections, are deferred payments (Babich and Tang 2012), as well as supplier certification, audits, and contingency payments (Chen and Lee 2016). The age and country of the supplier and 
its relationship type with the buyer are some factors that determine the incentives for suppliers to adhere to environmental standards when buyers request it (Delmas and Montiel 2009). If we focus on buyers, brand visibility and value, serving for European markets, and the density of NGOs in the country where the buyer has its headquarters increase their sustainable sourcing practices (Thorlakson et al. 2018). Suppliers are more likely to be compliant if they are in a more regulated country, with higher freedom of press, and producing for buyers based in wealthier countries with socially aware consumers (Toffel et al. 2015). In our paper we find a relationship between unauthorized subcontracting and the buyer's popularity; when the buyer is a major brand that can suffer reputation damage, the penalty for unauthorized subcontracting is higher and so its probability decreases.

With regard to supply chain structure, Orsdemir et al. (2019) find the optimal vertical integration and compliance enforcement decision as a function of both the probability and the economic impact of the public disclosure of a violation of standards. They conclude that supply chain partnership can greatly improve an industry's compliance. Different sourcing policies and the influence of supplier competition on the supplier's willingness to switch to a sustainable process are studied in Agrawal and Lee (2019). Greater downstream competition, a more concentrated supplier base, and a less flexible supply chain make a retailer more likely to source responsibly (Guo et al. 2016). In a multi-tier supply chain, increased pressure from external stakeholders (consumers, NGOs, and governments) can decrease supply chain responsibility when the manufacturer shifts from directly monitoring all the supply chain to delegating such inspections (Huang et al. 2017). However, all these works refer to supply chains in which all the tiers are known to the buyer, as opposed to our work, in which buyers are not aware of the existence of second tier suppliers.

\section{Research Setting \\ 3.1. Data Collection}

The data for this paper was obtained from M., a global supply chain manager (or "middleman") located in Asia that links buyers to suppliers and supervises the entire production process. The middleman groups the buyer accounts into different lines of business. The dataset used in our analysis represents all the orders in one line of business, L., which is mostly mass-market apparel products for (lesser-known) brands in North America. The buyers and product categories in this line of business are further described in Tables 4 and 5 .

The middleman maintains a list of authorized factories. These are factories that have passed a building compliance inspection. ${ }^{1}$ The middleman also performs a conformity audit of each order to

\footnotetext{
${ }^{1}$ The suppliers are aware that this list exists and can request it at any point in time.
} 
ensure that it meets the agreed specifications. ${ }^{2}$ The conformity audits of the orders are independent from the compliance inspection of the facilities. The latter happen infrequently (e.g., once a year) and are performed by building inspectors. In contrast, the conformity audits are performed by employees of the middleman for each order. These audits are usually preannounced and scheduled during the order production to correct any defects.

In general, buyers allow their suppliers to use a third-party subcontractor to fulfill an order but the supplier is expected to inform the buyer via the middleman. In practice, suppliers only inform the buyer when the subcontractor belongs to the list of authorized factories. Hence, an instance of unauthorized subcontracting occurs when a supplier does not inform the buyer and the order is subcontracted to an unauthorized facility.

After the Rana Plaza collapse, the line of business L. decided to record when orders were subcontracted to unauthorized factories, i.e., factories that were not on the authorized list. This information was gathered during the routine conformity audit of each order. Suppliers were not informed that their unauthorized subcontracting practices were being recorded and no penalty was applied. In other words, the suppliers saw no changes and they continued with their regular practices. In particular, if an order was subcontracted, the supplier would tell the conformity auditor where it had been sent, just as they did prior to this study. ${ }^{3}$ Figure 1 shows a diagram of the process through which buyers place orders to suppliers via the middleman.

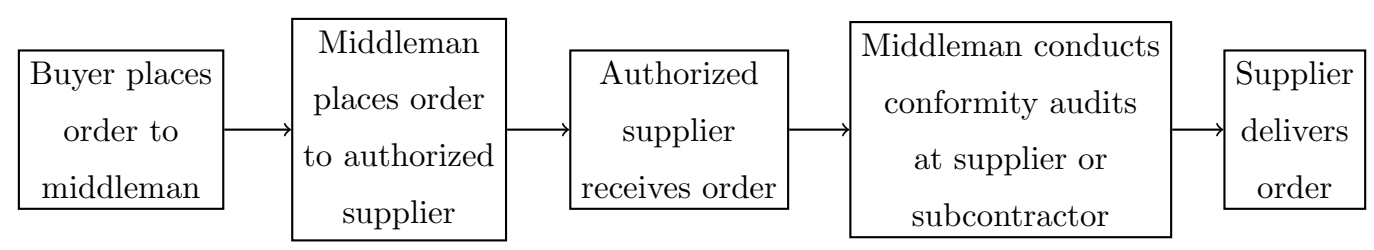

Figure 1 Diagram of the process of a buyer placing an order through the middleman $\mathrm{M}$.

\subsection{Data Description and Limitations}

Our data consists of all the orders delivered by the line of business L. in the eight months between October 2013 and May 2014. There are 32,477 orders that span 226 factories, 30 buyers, and 34 categories. An order represents one observation in our dataset and it is defined as a purchase request of an SKU from a buyer to a supplier through the middleman. The data contains characteristics

\footnotetext{
${ }^{2}$ According to ISO 9000:2005 definition 3.6.1, conformity is fulfillment of a requirement. In this paper we reserve the term "conformity" for order-level requirements and we use the term "compliance" for factory-level adherence to (established) building, labor, and environmental regulations.

${ }^{3}$ If an order was subcontracted, the conformity audit was performed at the subcontractor.
} 
of each order, the (original) factory where it was allocated, and the identification of the buyer. ${ }^{4}$ There is also a binary variable $\left(U S C_{i j}\right)$ stating whether the order was subcontracted (YES=1). A sample of an observation (order) is given in Table 1. An additional dataset corresponding to orders delivered between November 2010 and October 2013 was available. However, it did not contain any information on unauthorized subcontracting, just order characteristics. This dataset was used to compute the historical prices and specialization of each factory.

\begin{tabular}{lllll}
\hline Factory ID & Factory capacity & Factory country & Buyer ID & Product category \\
XXXXXX & $10^{5}$ units/month & Vietnam & YYYYYY & Sleepwear \\
\hline Quantity & Price & PO date & Scheduled due date & Delivery date \\
144 units & ZZZ USD/unit & $2013-09-10$ & $2013-12-12$ & $2013-12-12$ \\
\hline Unauthorized subcontracting & (USC) & & \\
YES & & & \\
\hline Table 1 & Example of one order. The factory, buyer and price information have been disguised.
\end{tabular}

Note that noncompliance can only happen at unauthorized facilities, as was the case in all the disasters described in $\S 1$, but not all unauthorized facilities are necessarily non-compliant. In other words, noncompliance implies unauthorized subcontracting but the converse implication is not necessarily true. Hence, unauthorized subcontracting is not a direct measure of noncompliance but rather should be seen as a proxy for increased compliance risk. Alternatively, an incident of unauthorized subcontracting can be seen as a lack of supply chain visibility.

In terms of limitations, the data contains neither information on who the subcontractor was or the date of the conformity audit, nor information about any orders that the factories produced outside our dataset. Per our conversations with middleman M., buyers place their orders directly to the suppliers when the product is very well established so advanced planning is easier and its production does not require as much supervision. Therefore, the orders that we cannot observe do not differ much from the orders in the dataset except for the novelty of the product. It is possible that buyers use other middlemen for some orders but Table 2 shows that middleman M. uses a large portion of its suppliers' available capacity. Nevertheless, because of these limitations, we refrain from making general industry statements and the findings are contingent to our specific dataset.

\subsection{Data Exploration}

Figure 2 shows a histogram of the percent of orders that each factory subcontracted without authorization. As shown in the figure, unauthorized subcontracting is not evenly distributed among factories. While some factories never subcontracted any order (Type A), others decided to subcontract on an order-by-order basis (Type B), and a third group of factories subcontracted all of their

${ }^{4} 60$ observations were discarded because their scheduled delivery date was earlier or equal to their purchase order date. According to the middleman, these correspond to orders that had been placed to suppliers (over phone or e-mail) but not introduced in the system until after they were finished. 


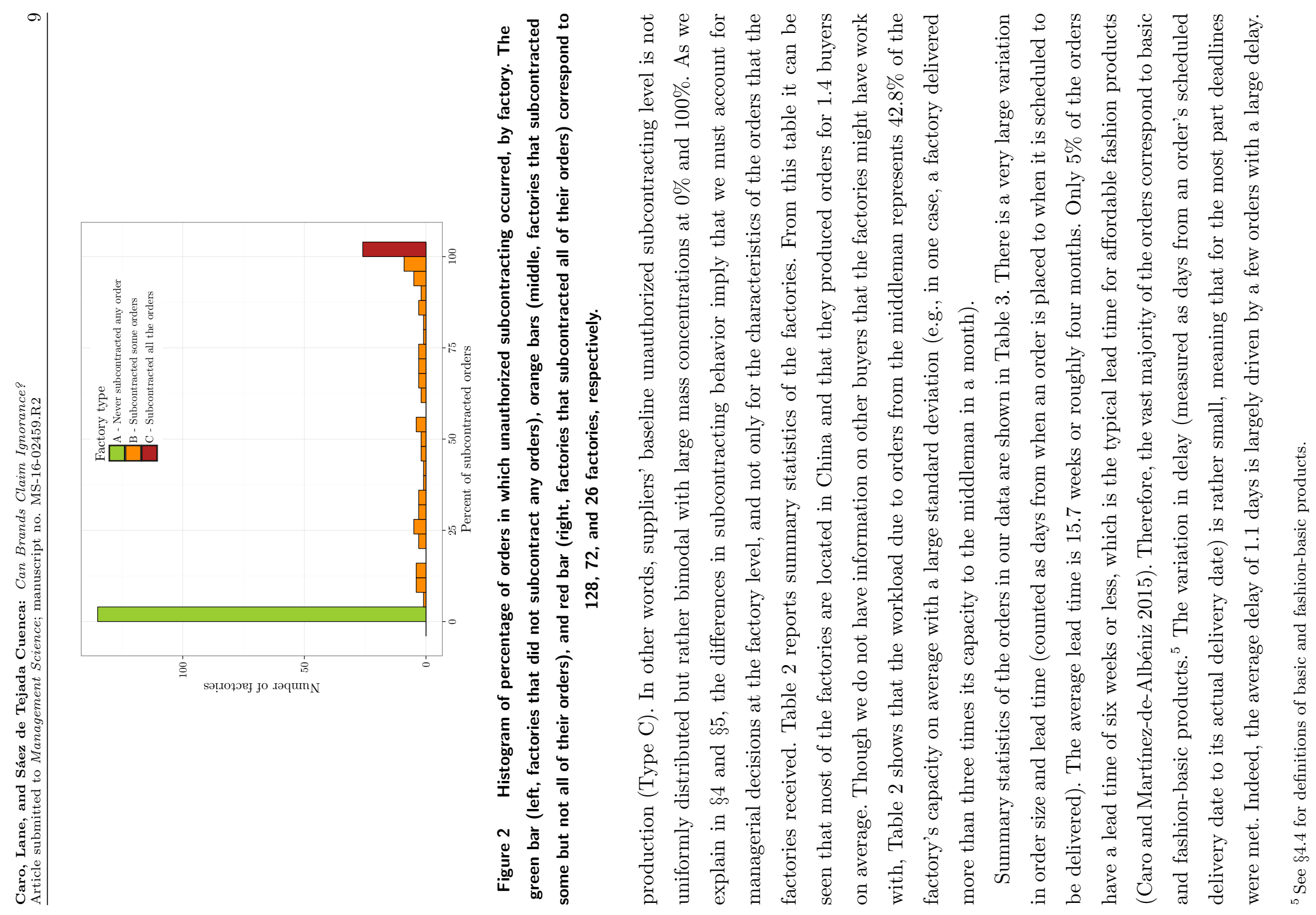




\begin{tabular}{|c|c|c|c|c|c|c|c|}
\hline & Mean & St. dev. & Min. & Max. & $\%$ Factories & $\%$ Orders & $\%$ USC \\
\hline \multicolumn{8}{|l|}{ Factory descriptive statistics: } \\
\hline Number of orders delivered & 143.4 & 270.6 & 1 & 2772 & - & - & - \\
\hline Number of categories produced & 2.8 & 2.1 & 1 & 10 & - & - & - \\
\hline Number of buyers served & 1.4 & 0.99 & 1 & 11 & - & - & - \\
\hline Orders from major brands (\%) & 1.9 & 10.4 & 0 & 100 & - & - & - \\
\hline Capacity (monthly units) & 389,889 & 864,023 & 10,000 & $10,000,000$ & - & - & - \\
\hline Utilization in a non-idle month (\%) & 42.8 & 51.6 & 0.21 & 322.0 & - & - & - \\
\hline \multicolumn{8}{|l|}{ Factory type: } \\
\hline Type A - Never subcontracted & - & - & - & - & 56.6 & 35.6 & 0 \\
\hline Type B - Sometimes subcontracted & - & - & - & - & 31.9 & 57.9 & 51.7 \\
\hline Type C - Always subcontracted & - & - & - & - & 11.5 & 6.4 & 100 \\
\hline \multicolumn{8}{|l|}{ Factory location: } \\
\hline Bangladesh & - & - & - & - & 10.6 & 12.7 & 0.15 \\
\hline Cambodia & - & - & - & - & 5.8 & 5.4 & 52.0 \\
\hline China & - & - & - & - & 59.7 & 54.8 & 48.0 \\
\hline Indonesia & - & - & - & - & 6.6 & 13.1 & 16.0 \\
\hline Vietnam & - & - & - & - & 9.3 & 9.1 & 54.5 \\
\hline Other & - & - & - & - & 8.0 & 4.9 & 4.6 \\
\hline
\end{tabular}

Table 2 Description of the factories. Utilization in a non-idle month is the number of units delivered during every calendar month divided by the factory's monthly capacity, averaged over the months in which factories delivered at least one order. A major brand is one that has its own stores and website (see $\S 4.6$ ). The factory types are defined in Figure 2.

\begin{tabular}{lcccc} 
& Mean & St. dev. & Min. & Max. \\
\hline Order size (units) & 2508 & 5828 & 1 & 240,491 \\
Order lead time (days) & 110 & 46 & 1 & 503 \\
Order delivery delay (days) & 1.1 & 7.3 & -84 & 141 \\
\hline
\end{tabular}

Table 3 Description of the orders. Delivery delay equals (actual) delivery date minus scheduled delivery. Lead time equals scheduled delivery minus purchase order date.

Table 4 shows summary statistics of the buyers. It can be seen that, on average, the buyers ordered products in 3.4 categories and that they worked with 10.7 different factories. The vast majority of the orders came from buyers located in North America, and most of the buyers represent brands that do not have their own stores or website. These smaller brands are more likely to use the middleman M. for most of their sourcing, though there is no exclusivity agreement in place. Finally, Table 5 contains a list of the top product categories in the data.

\begin{tabular}{|c|c|c|c|c|c|c|c|}
\hline \multirow{2}{*}{\multicolumn{8}{|c|}{ Buyer descriptive statistics: }} \\
\hline & & & & & & & \\
\hline Orders placed & 1080.6 & 2383.7 & 1 & 9648 & - & - & - \\
\hline Number of product categories ordered & 3.4 & 3.3 & 1 & 11 & - & - & - \\
\hline Number of factories engaged with & 10.7 & 17.5 & 1 & 60 & - & - & - \\
\hline Buyer recognition: & & & & & & & \\
\hline Major brand (has own stores and website) & - & - & - & - & 46.7 & 2.2 & 5.9 \\
\hline Not major brand & - & - & - & - & 53.3 & 97.8 & 37.1 \\
\hline Buyer location: & & & & & & & \\
\hline North America & - & - & - & - & 63.4 & 99.3 & 36.6 \\
\hline Asia & - & - & - & - & 13.3 & 0.18 & 0.0 \\
\hline Europe & - & - & - & - & 10.0 & 0.21 & 0.0 \\
\hline Other & - & - & - & - & 13.3 & 0.35 & 0.0 \\
\hline
\end{tabular}

Table 4 Description of the buyers. 
Caro, Lane, and Sáez de Tejada Cuenca: Can Brands Claim Ignorance?

\begin{tabular}{|c|c|c|c|c|c|}
\hline & $\%$ Orders & $\%$ Units & \# Factories & \# Buyers & $\%$ USC \\
\hline Bottoms & 6.7 & 9.7 & 72 & 9 & 45.1 \\
\hline Dresses & 3.2 & 1.9 & 35 & 8 & 39.5 \\
\hline Jackets & 1.6 & 1.2 & 32 & 8 & 52.4 \\
\hline Pants & 8.3 & 7.1 & 79 & 8 & 34.9 \\
\hline Polos & 6.2 & 6.1 & 25 & 7 & 60.5 \\
\hline Sets & 11.8 & 11.2 & 42 & 2 & 65.0 \\
\hline Shirts & 17.0 & 8.6 & 63 & 22 & 23.4 \\
\hline Sleepwear & 6.8 & 11.5 & 12 & 4 & 21.0 \\
\hline Swimwear & 3.0 & 2.8 & 13 & 2 & 21.8 \\
\hline Tops & 19.8 & 23.7 & 126 & 11 & 32.1 \\
\hline T-shirts & 6.5 & 3.9 & 33 & 8 & 19.4 \\
\hline Other & 9.1 & 12.2 & 97 & 14 & 35.7 \\
\hline
\end{tabular}

Table 5 Descriptive statistics of the top 11 product categories. \# Factories is the number of factories that produced products in a category. \# Buyers is the number of buyers that placed orders in a category.

\section{Hypotheses}

The dependent variable in our analysis is the binary variable $U S C_{i j}$ that equals 1 if unauthorized subcontracting occurred, i.e., it equals 1 when order $j$ of supplier $i$ was subcontracted to a factory that was not on the authorized list of the middleman M. We propose six hypotheses to explain the main drivers of $U S C_{i j}$ that we test using the variables described below. Note that the academic literature on unauthorized subcontracting is meager, so we support some of our hypotheses drawing from the related literature on compliance.

\subsection{State Dependence}

HYPOTHESIS 1. Unauthorized subcontracting is more likely when the previous order in the same factory was subcontracted.

A factory can be seen as a queueing system in which the state is given by the queue length or workload (Buzacott and Shanthikumar 1993). When the queue of orders becomes too long, unauthorized subcontracting is used as an overflow valve (Labowitz and Baumann-Pauly 2014, 2015). One can think of an implicit threshold that triggers this mechanism. When the queue length exceeds the threshold, the supplier resorts to unauthorized subcontracting to bring the system back under control. Then, unauthorized subcontracting must exhibit state dependence because two consecutive orders see similar workloads when they join the queue, especially if the factory is operating close to capacity. Indeed, if the queue exceeds the threshold for one order, then it is likely that the queue will exceed the threshold for the next order as well. ${ }^{6}$

Factories might operate close to capacity due to several factors. First, more orders means more business, which eventually translates into higher revenues. Second, rejecting an order can set a precedent and factories might fear that the buyer will not place orders there in the future. In

${ }^{6}$ In the classic $M / M / 1$ queue, the chance that an incoming order finds a queue longer than the previous order is equal to $\rho /(1+\rho)$, which is increasing in the utilization level $\rho$. 
particular, the factories in our dataset dedicate a substantial amount of their capacity to the middleman M. and typically produce for a very small number of buyers (see Table 2). This is also shown in other studies surveying suppliers in developing countries (Vaughan-Whitehead and Pinedo Caro 2017, Anner 2019). Third, some factories exhibit poor production planning, such as lack of awareness of the critical path and inaccurate forecasting of the necessary time to complete an order (Hurst et al. 2005). Finally, buyers that have invested in improving the compliance of their suppliers inadvertently make those suppliers more attractive to other "free-riding" buyers that will also want to place their orders there (Greenhouse 2013, Plambeck and Taylor 2016).

We test Hypothesis 1 by introducing an autoregressive term $U S C_{i, j-1}$ in our regression model. We also include factory fixed effects and several sets of dummies in order to distinguish between structural and spurious dependence (Heckman 1981). We acknowledge that in addition to high utilization, there can be other causes of state dependence. An alternative explanation is that factories could be making subcontracting decisions for batches of orders instead of one by one. For instance, if two consecutive orders are color variations of the same garment, it would not make sense (in terms of setup costs) for the supplier to subcontract only one of them.

\subsection{Price Pressure}

Hypothesis 2. Unauthorized subcontracting is more likely for orders that have a lower unit price.

A lower price makes an order less profitable and could give the supplier incentives to divert it to an unauthorized third party which has lower production costs by being non-compliant (Anas 2019). This is a common view in the public press (Goodman 2013) and is supported by industry-wide surveys (Barrientos and Smith 2007, Vaughan-Whitehead and Pinedo Caro 2017). Several studies in the operations literature report results linking price pressure to non-compliant behavior. For instance, Jiang (2009) reports that price pressure is one of the main reasons that led to violations of supplier codes of conduct. Similarly, Tang and Babich (2014) mention that pressure from Western manufacturers to deliver products at persistently lower prices is a crucial factor that pushes Chinese suppliers to "cut corners". In contrast, the work by Plambeck and Taylor (2016) shows that, under a certain backfiring condition, price pressure could lead to less unauthorized subcontracting, which could seem to run against Hypothesis 2. However, the backfiring condition is unlikely to hold in our setting since there was no additional compliance inspection effort when the data was collected and unauthorized subcontracting was not penalized.

We measure price pressure by comparing the unit price of an order with the historical average in the same factory and category. Specifically, let Price $_{i j}$ be the unit price of order $j$ at factory $i$. Let $c$ be the product category of order $j$ and let $P_{i}^{c}$ be the average price for category $c$ at factory $i$ using 
all the orders of category $c$ delivered by factory $i$ during the calendar year prior to the delivery

date of order $j$. Then we define the continuous variable RelPriceF $C_{i j}=\frac{\text { Price }_{i j}-P_{i}^{c}}{P_{i}^{c}}$. Note that the definition of RelPriceFC $C_{i j}$ is consistent with the notion of price pressure described in Jiang (2009) where factory managers felt pressure when the price they were paid for an order was lower than their usual price for that type of product. We test alternative measures of price pressure as robustness checks in the e-companion.

\subsection{Time Pressure}

Hypothesis 3. Unauthorized subcontracting is more likely for orders that have a short lead time.

An important reason why factories engage in (authorized) subcontracting is to minimize the completion time of their orders (Vairaktarakis 2013). The same reason holds for unauthorized subcontracting. Moreover, the market is changing rapidly: tighter lead times because of later sample approval and last-minute alterations to product specifications put increased pressure on factories. Buyers will often delay their purchasing decisions as long as possible to observe early demand or to react to what their competitors do (Ashida and Plinke 2004, Barrientos and Smith 2007, VaughanWhitehead and Pinedo Caro 2017, Anner 2019). For their part, suppliers are reluctant to reject orders for fear of lost business (cf. §4.1), so they accept them even if the lead time is infeasible. Vaughan-Whitehead and Pinedo Caro (2017) found that most suppliers surveyed considered that $30-50 \%$ of orders they received had insufficient lead times and $31 \%$ turned to subcontracting. Similarly, Anner (2019) estimates that from 2011 to 2016 lead times decreased by 8\%, and this time pressure impacts workers in the form of overtime and unauthorized subcontracting.

We test Hypothesis 3 using the variable LeadTime $_{i j}$, which counts the number of days between the date when order $j$ was placed to factory $i$ and the order's scheduled delivery date. We use this same variable to test a competing hypothesis for lead times that is described next.

\subsection{Fashion vs. Basics}

HYPOTHESIS 4. Unauthorized subcontracting is more likely for orders that have a long lead time.

We propose a competing hypothesis regarding lead times. A key attribute of mass-market apparel products is the fashion component, i.e., how "fashionable" or "trendy" a product is (Abernathy et al. 1999). This attribute can be thought as a continuous variable from $0 \%$ to $100 \%$ fashionable. Measuring it can be hard, but a good proxy is lead times (Caro and Martínez-de-Albéniz 2015, Lago et al. 2016). On one end of the spectrum are the affordable fashion products that follow the high-end fashion trends, and therefore, must be produced with short lead times of typically six weeks or less (Caro 2012). On the other end are the basic items that correspond to perennial 
products with little novelty that are produced every season (e.g., plain color T-shirts) and have lead times of six months or more. In between fashion and basics there is a large segment that can be cataloged as fashion-basics, which are variations of basics with some minimal added design that give a "feel for fashion" (H\&M 2010). Fashion-basics usually have lead times ranging from two to six months depending on their trendiness.

Informal factories that act as unauthorized subcontractors are mostly small and less sophisticated (Labowitz and Baumann-Pauly 2015, Donaldson 2017). These factories are more prone to focus on basics because they lack the capability to produce fashion items, which have special aesthetic elements to make them unique. Hence, one can postulate that — all else being equal, including price - unauthorized subcontracting increases when the lead time is longer because it corresponds to orders of less sophisticated products (basics) produced at informal factories. Note that an alternative explanation for this effect is recency bias, i.e., humans' tendency to heavily discount past information (Cushing and Ahlawat 1996, Erev and Haruvy 2013). In other words, orders that have been placed long ago in the past are not salient to factory managers. These orders remain forgotten and are not taken into account in production planning so managers resort to unauthorized subcontracting when they finally notice an approaching deadline.

\subsection{Factory Specialization}

HYPOTHESIS 5. Unauthorized subcontracting is more likely for orders of categories other than the factory's specialization.

In the strategy literature it is well understood that specialization can be a source of competitive advantage (Dyer 1996). Moreover, production switchovers are costly in a multi-product manufacturing setting and are hard to manage (Rosa-Hatko and Gunn 1997, Cheng et al. 2000), which reinforces the specialization in a smaller set of products. Once a factory is specialized, activities that are outside its core are natural candidates to be outsourced to a third party. The latter is supported by the usual outsourcing frameworks in operations strategy (Van Mieghem 2008).

The factories in our dataset exhibit a high degree of specialization. Table 2 shows that the factories produce fewer than three product categories on average. In fact, $73 \%$ of the factories produced at most three product categories, and only two factories produced 10 different product categories. Therefore, we hypothesize that an order of a product category that a factory does not produce very often may have a higher probability of being subcontracted because it is outside the factory's core activities. A complementary view is that the factory might not have the technical capability, or might simply want to avoid production switchovers, so this specific order is more complex for the factory. Note that the degree of complexity is specific to each factory-category 
pair. For instance, an order of pants may be complex for a factory that is specialized in sweaters, but not complex for a factory that regularly produces pants.

To measure factory specialization, we need to take into account what types of products each factory produces more often. Hence, we define PropThisCategory $y_{i j}$ as the proportion of orders at factory $i$ of the same category as order $j$ during the calendar year prior to when order $j$ was delivered. We use the continuous variable PropThisCategory $y_{i j}$ to test Hypothesis 5.

\subsection{Buyer Reputation}

HYPOTHESIS 6. Unauthorized subcontracting is less likely when the buyer is a well-known brand.

The evidence in practice has demonstrated that stronger brands face a higher cost and more reputation damage when disasters related to non-compliance occur. After the Rana Plaza collapse, some of the famous retailers whose products were being made there had to pay compensations to families of the victims (Butler 2014, Smithers 2015). There is also evidence that "name and shame" schemes are more effective with high-profile brands (Lee and Plambeck 2009). For instance, Apple agreed to monitor the pollution of its factories after being exposed by the Institute of Public and Environment Affairs (IPE), which is a nonprofit organization based in China (Nuttall 2012).

Given the empirical evidence, a standard assumption in supply chain compliance models is that the buyer faces a penalty if the supplier commits a compliance violation (Plambeck and Taylor 2016, Guo et al. 2016, Caro et al. 2018, Huang et al. 2017). This penalty is higher for buyers that have more at stake and intuitively it should lead to actions that induce the supplier to be more socially responsible. Indeed, Plambeck and Taylor (2016) show that unauthorized subcontracting is less frequent when the buyer has more at stake as long as compliance auditing efforts do not backfire. ${ }^{7}$ Similarly, Huang et al. (2017) find that greater pressure focused on the retailer decreases the chance of a violation in the supply chain.

We postulate that unauthorized subcontracting is less likely for an order placed by a wellknown brand. This could be because the well-known brand will exert a higher effort in preventing irresponsible behavior, as in the single-period models cited above, or it could simply be because the damage cost of the supplier is correlated with the violation penalty faced by the buyer. Indeed, suppliers know that, should a disaster happen, the attention of the press will be higher for orders of well-known brands and any penalty faced by these brands could spill over to them.

Some of the buyers placing orders to factories in our data correspond to major retailing brands, while others are distributors or brands that are not as well-known to the public. To test Hypothesis 6 , we use the variable BuyerIsMajor Brand ${ }_{i j}$, which takes value 1 if the buyer that placed order $j$

\footnotetext{
${ }^{7}$ Proposition 12 in Plambeck and Taylor (2016) requires that the supplier does not have incentives to hide its behavior,
} which was the case in our setting. 
at factory $i$ has its own website and its own network of stores, and 0 otherwise. The buyers in our data that we labeled as major brands correspond to retailers with hundreds of stores in multiple countries and an online store in their website, whereas the other buyers sold through third-party retail channels, e.g., department stores. $^{8}$.

\section{Methods and Results}

\subsection{Model Specification}

We propose the following linear regression model to explain unauthorized subcontracting:

$$
U S C_{i j}=\alpha U S C_{i, j-1}+\beta x_{i j}+f_{i}+\varepsilon_{i j},
$$

where $f_{i}$ are time-invariant factory fixed effects and $\varepsilon_{i j}$ is the error term. The vector $x_{i j}$ contains the independent variables used to test the hypotheses, i.e., RelPriceFC $C_{i j}$, LeadTime ${ }_{i j}$, PropThisCategory $_{i j}$, and BuyerIsMajorBrand ${ }_{i j}$, as well as the control LogOrderSize ${ }_{i j}$, which is the logarithm of the size of order $j$ at factory $i$. Table 6 shows descriptive statistics of these variables. Collinearity is discussed in the e-companion.

\begin{tabular}{|c|c|c|c|c|c|c|c|c|c|}
\hline & Mean & St. dev. & Min. & Max. & & Mean & St. dev. & Min. & Max. \\
\hline USC & 0.364 & 0.481 & 0 & 1 & USC & 0.517 & 0.500 & 0 & 1 \\
\hline RelPriceFC & -0.008 & 0.253 & -0.879 & 4.103 & RelPriceFC & -0.011 & 0.264 & -0.879 & 4.103 \\
\hline LeadTime & 110 & 46 & 1 & 503 & LeadTime & 110 & 40 & 2 & 436 \\
\hline PropThisCategory & 0.610 & 0.351 & 0.001 & 1 & PropThisCategory & 0.589 & 0.359 & 0.001 & 1 \\
\hline BuyerIsMajorBrand & 0.022 & 0.147 & 0 & 1 & BuyerIsMajorBrand & 0.019 & 0.135 & 0 & 1 \\
\hline \multirow[t]{2}{*}{ LogOrderSize } & 6.695 & 1.626 & 0 & 12.390 & LogOrderSize & 6.665 & 1.606 & 0 & 12.390 \\
\hline & Mean & St. dev. & Min. & Max. & & Mean & St. dev. & Min. & Max. \\
\hline USC & 0.059 & 0.235 & 0 & 1 & USC & 0.371 & 0.483 & 0 & 1 \\
\hline RelPriceFC & 0.082 & 0.119 & -0.335 & 0.808 & RelPriceFC & -0.010 & 0.254 & -0.879 & 4.103 \\
\hline LeadTime & 124 & 49 & 9 & 436 & LeadTime & 110 & 46 & 1 & 503 \\
\hline PropThisCategory & 0.869 & 0.313 & 0.022 & 1 & PropThisCategory & 0.604 & 0.349 & 0.001 & 1 \\
\hline BuyerIsMajorBrand & 1 & 0 & 1 & 1 & BuyerIsMajorBrand & 0 & 0 & 0 & 0 \\
\hline LogOrderSize & 6.878 & 1.092 & 3.296 & 9.855 & LogOrderSize & 6.691 & 1.636 & 0 & 12.390 \\
\hline
\end{tabular}

Table 6 Descriptive statistics of the regression variables, using the full dataset (top left), the subsample of type B factories (top right), orders delivered to buyers who are major brands (bottom left), and orders delivered to buyers who are not major brands (bottom right).

We use a linear model in order to introduce multiple fixed effects. An alternative probit model with random effects is described in the e-companion. The factory-level fixed effect $f_{i}$ in Equation (1) captures the factory effect that is apparent in Figure 2 and it accounts for the idiosyncratic baseline of unauthorized subcontracting of each factory, i.e., the factory's managerial decision on how often to subcontract on average. This (unobservable) fixed effect can also be viewed as the supplier's

\footnotetext{
${ }^{8}$ It is common in the literature to identify major buyers as those that are publicly traded. However, such criteria does not discriminate in our setting because $99.8 \%$ of the orders were placed by publicly traded companies; most non-major brands in our dataset are subsidiaries of publicly traded companies
} 
intrinsic ethical level, which is a common assumption in theoretical models (e.g., see Chen and Lee 2016). To mitigate possible sources of omitted variable bias, we introduce additional dummy variables for product category, delivery month, and buyer. ${ }^{9}$ Finally, factories may be strategic about which orders to subcontract depending on the order size. Therefore, we control for order size using the variable LogOrderSize $e_{i j}$. We opt for a logarithmic form given the large variability of order quantities.

Since the right hand side in Equation (1) has a lagged variable and a fixed effect, we rely on the first difference equation $\Delta U S C_{i j}=\alpha \Delta U S C_{i, j-1}+\beta \Delta x_{i j}+\Delta \varepsilon_{i j}$ and the Arellano-Bond estimator (Wooldridge 2010, Greene 2003, Cameron and Trivedi 2005, 2010). Following the Arellano-Bond approach, the correlation between $\Delta U S C_{i, j-1}$ and $\Delta \varepsilon_{i j}$ is addressed by using $U S C_{i, j-2}$ as an instrumental variable (IV). This is a strong instrument, as $\Delta U S C_{i, j-1}$ and $U S C_{i, j-2}$ are highly correlated. It is also a valid one as it is uncorrelated with the error term, insofar the errors $\Delta \varepsilon_{i j}$ are not autocorrelated (we check the veracity of this assumption in the e-companion).

There is a possibility of simultaneity between price and unauthorized subcontracting. If either the buyer or the middleman have some visibility on a factory's past subcontracting behavior, they will use this information to set the prices they offer, i.e., a factory's past unauthorized subcontracting may affect the current prices of the orders it receives. For instance, the buyer can decide to offer a low price for an order to a supplier if it suspects that the supplier will likely subcontract it, and so it will be less costly to produce if not all safety standards are met. To account for the possible endogeneity of the price pressure variable, we also use an IV approach: RelPriceFC $C_{i, j-2}$ will serve as an instrument for $\Delta$ RelPrice $F C_{i, j}$. Similarly, a factory's past unauthorized subcontracting may affect its current orders' lead times. Therefore, we also use an IV approach to tackle the possible endogeneity of the lead time variable: we instrument $\Delta$ LeadTime $_{i, j}$ with its second lag, LeadTime $_{i, j-2}$. Note that, to be able to include second lags of the dependent variable and the price and lead time covariates as instruments, we need to remove the first two observations of each factory from the regression. We discuss the possibility that the variable BuyerIsMajor Brand ${ }_{i j}$ is also endogenous in the e-companion.

The coefficients of our regression model were computed using generalized method of moments in Stata 14.2 with the command xtabond (Baum et al. 2015). In the e-companion, we test the robustness of our results to a different estimation technique, the two-step least squares (or Hsiao estimator).

\footnotetext{
${ }^{9}$ When buyer dummies are introduced we have to drop the variable BuyerIsMajorBrand ${ }_{i j}$ due to collinearity.
} 


\subsection{Results}

Table 7 shows the coefficient estimates of the Arellano-Bond regression. We show the results for two datasets: (i) including all the factories in our data, and (ii) including only type B factories (those that subcontracted some, but not all, of their orders). The reason for running our regression using this subsample is that these are the factories whose unauthorized subcontracting behavior was established on an order-by-order basis and not as a decision that determined all their orders, so individual order characteristics should have a stronger correlation with the decision to subcontract than for factories whose behavior is fixed and constant over time.

\begin{tabular}{lcccc} 
& \multicolumn{5}{c}{ Unauthorized subcontracting } \\
\cline { 2 - 5 } & $(1)$ & $(2)$ & $(3)$ & $(4)$ \\
\hline USC $_{i, j-1}$ & $0.315^{* * *}$ & $0.313^{* * *}$ & $0.314^{* * *}$ & $0.310^{* * *}$ \\
& $(0.0257)$ & $(0.0257)$ & $(0.0225)$ & $(0.0225)$ \\
RelPriceFC & $-0.130^{* *}$ & $-0.134^{* *}$ & $-0.139^{* *}$ & $-0.143^{* *}$ \\
& $(0.0490)$ & $(0.0487)$ & $(0.0500)$ & $(0.0527)$ \\
& & & & \\
LeadTime & $0.000842^{* * *}$ & $0.000839^{* * *}$ & $0.000988^{* *}$ & $0.000966^{* *}$ \\
& $(0.000239)$ & $(0.000231)$ & $(0.000356)$ & $(0.000352)$ \\
PropThisCategory & 0.0324 & 0.00568 & 0.00902 & -0.00796 \\
& $(0.0325)$ & $(0.0300)$ & $(0.0303)$ & $(0.0308)$ \\
BuyerIsMajorBrand & $-0.0806^{* * *}$ & $-0.0767^{* * *}$ & $-0.0858^{* * *}$ & \\
& $(0.0150)$ & $(0.0211)$ & $(0.0190)$ & \\
LogOrderSize & -0.00417 & -0.00423 & -0.00395 & -0.00415 \\
& $(0.00277)$ & $(0.00282)$ & $(0.00240)$ & $(0.00259)$ \\
\hline Category dummies & No & Yes & Yes & Yes \\
Month dummies & No & No & Yes & Yes \\
Buyer dummies & No & No & No & Yes \\
\hline$N$ & 31955 & 31955 & 31955 & 31955 \\
\hline Robust standard errors in parentheses & \multicolumn{3}{c}{} \\
${ }^{*} p<0.05,{ }^{* *} p<0.01,{ }^{* * *} p<0.001$ & & & \\
\hline
\end{tabular}

\begin{tabular}{lcccc} 
& \multicolumn{4}{c}{ Unauthorized subcontracting } \\
\cline { 2 - 5 } & $(1)$ & $(2)$ & $(3)$ & $(4)$ \\
\hline USC $_{i, j-1}$ & $0.314^{* * *}$ & $0.312^{* * *}$ & $0.314^{* * *}$ & $0.310^{* * *}$ \\
& $(0.0246)$ & $(0.0246)$ & $(0.0203)$ & $(0.0204)$ \\
RelPriceFC & $-0.139^{* *}$ & $-0.145^{* *}$ & $-0.146^{* *}$ & $-0.150^{* *}$ \\
& $(0.0511)$ & $(0.0498)$ & $(0.0496)$ & $(0.0532)$ \\
& & & & \\
LeadTime & $0.000831^{* *}$ & $0.000837^{* * *}$ & $0.00109^{* *}$ & $0.00107^{* *}$ \\
& $(0.000259)$ & $(0.000247)$ & $(0.000363)$ & $(0.000366)$ \\
& & & & \\
PropThisCategory & 0.0537 & 0.0191 & 0.0149 & -0.0131 \\
& $(0.0508)$ & $(0.0570)$ & $(0.0556)$ & $(0.0564)$ \\
BuyerIsMajorBrand & $-0.0830^{* *}$ & $-0.0831^{* *}$ & $-0.0998^{* *}$ & \\
& $(0.0271)$ & $(0.0322)$ & $(0.0305)$ & \\
LogOrderSize & -0.00574 & -0.00585 & -0.00498 & -0.00553 \\
& $(0.00370)$ & $(0.00376)$ & $(0.00309)$ & $(0.00340)$ \\
\hline Category dummies & No & Yes & Yes & Yes \\
Month dummies & No & No & Yes & Yes \\
Buyer dummies & No & No & No & Yes \\
\hline$N$ & 18625 & 18625 & 18625 & 18625 \\
\hline Robust standard errors in parentheses & & & \\
$*$ & $*<0.05,{ }^{* *} p<0.01,{ }^{* * *} p<0.001$ & & & \\
\hline
\end{tabular}

Table 7 Coefficients of the Arellano-Bond regression, using all the data (left) and the subsample of type B factories (right).

As shown in the left panel of Table 7, the coefficient for the lagged dependent variable is positive and highly significant, ranging from 0.310 to 0.315 , robust to the inclusion of category, buyer and month dummies. The interpretation of this coefficient is that, when a factory subcontracts an order, the next order this factory delivers is about 31 percentage points more likely to be subcontracted too than if the previous order had not been subcontracted (all else equal). The $U S C_{i, j-1}$ coefficient is similar if we only use the 72 type $\mathrm{B}$ factories and is still highly significant $(p<0.001)$. Hence, we find support for Hypothesis 1 as unauthorized subcontracting in our dataset exhibits a high and significant level of state dependence. The magnitude of this coefficient must be emphasized. To see this, consider that the overall prevalence or baseline of unauthorized subcontracting is $36 \%$. Then, the state dependence coefficient almost doubles the chance of unauthorized subcontracting with respect to the baseline. 
The second largest coefficient in magnitude is that of price pressure. It ranges from -0.143 to -0.130 for the full sample and is statistically significant at the 0.01 level. This result supports Hypothesis 2 and means that, when a buyer offers a unit price for an order that is lower than the factory's usual price for that product category, the probability of unauthorized subcontracting is higher. For instance, if the price pressure of an order is such that the unit price is $25 \%$ lower than the usual price, the chance of unauthorized subcontracting would increase by at least $(-13.0) \times$ $(-25 \%)=3.3$ percentage points, or $9 \%$. When we consider only type B factories in the regression, the coefficients of the price pressure variable are larger in magnitude and range from -0.150 to -0.139 .

Regarding lead times, the coefficients of the variable LeadTime $_{i j}$ are positive and statistically significant at the 0.01 level, ranging from 0.000842 to 0.000988 . Hence, we find support for Hypothesis 4 and not for Hypothesis 3. When an order is placed earlier with respect to its scheduled due date, the probability that it is subcontracted is higher. Every extra day is associated with an increase in the probability of unauthorized subcontracting of around 0.09 percentage points, or $0.25 \%$. This estimate supports the notion that orders of basic (i.e., less sophisticated) products are more likely to be subcontracted than fashion items because the former have markedly longer lead times than the latter. For instance, the chance of unauthorized subcontracting for a basic product with a typical six-month lead time is $18 \%$ higher than the average order in our sample (cf. Table 3), all else being equal.

The coefficients for the binary variable BuyerIsMajorBrand $d_{i j}$ range from -0.0806 to -0.0767 $(p<0.001)$ for the full sample. Hence, an order for a major brand is about eight percentage points less likely to be subcontracted. Since the overall unauthorized subcontracting baseline is $36 \%$, we find that orders from major brands in the full sample are $22 \%$ less likely to be subcontracted. For the subsample of type B factories, the coefficient magnitude ranges from -0.0998 to -0.0830 . Like in the case of price pressure, type B factories are more sensitive to specific characteristics of the orders when making the decision of whether to subcontract them. Our findings support Hypotheses 6. We further explore the role of the buyer by considering time-varying buyer characteristics and a supplier-buyer panel structure in Appendix the e-companion.

Finally, the coefficient estimates for the variable PropThisCateg $_{i j}$ were statistically insignificant in all cases. Hence, we do not find support for Hypotheses 5 at the order level.

\section{Prediction}

In $\S 5$ we analyzed the factors driving unauthorized subcontracting. We now aim to predict which orders have a high probability of being subcontracted. In other words, would retailers be able to know that a certain order is likely to be subcontracted so to make better sourcing decisions? 
Predicting binary events is a deeply researched topic in finance, for instance to predict bankruptcy or financial distress (Sarkar and Sriram 2001, Alan and Lapré 2018), but now it is also becoming more common in other areas, including supply chain management. In fact, predicting unauthorized subcontracting was the original motivation of the middleman M. that sparked this research project. Our goal here is to show how well the middleman or a retailer could do with simple linear models based on the findings from $\S 5$. We acknowledge that more sophisticated models are likely to perform even better, but that is beyond the scope of this paper. We rather want to illustrate that middlemen and buyers could predict when orders might be subcontracted to better inform their purchasing decisions.

To study how much future unauthorized subcontracting can be predicted, we divide our data in two subsets, training and test. The training data is used to estimate the coefficients of a linear regression model, while the test data is used to make out-of-sample predictions and quantify how accurate they are. To divide the observations between training and test we sort them by order delivery date and then split it; the reason for not randomizing them before partitioning is that the goal of this analysis is using knowledge of the past to predict the future, so we need to keep the chronological order. To check the robustness of our prediction, we repeat this procedure several times using different proportions of data in each subset (from $20 \%$ training and $80 \%$ test, to $80 \%$ and $20 \%)$.

Once the data is divided, we fit four different linear models with the training dataset. First, a model containing the following variables: RelPriceFC $C_{i j}$, LeadTime Le $_{i j}$, PropThisCategory ${ }_{i j}$, BuyerIsMajorBrand ${ }_{i j}$, LogOrderSize ${ }_{i j}$, and a whole set of product category dummies. We call these order-level variables, since they vary order to order. Note that this model does not take into account any information about the factory's willingness to subcontract or not, but does contain, implicitly, information on the factory's reference prices and specialization. The second linear model we fit contains the previous variables, plus a set of factory dummies, which measure each factory's idiosyncratic baseline degree of unauthorized subcontracting during the training dataset months, representing its managerial decision on whether or not to subcontract, and how much. Third, we fit a linear model containing the order-level variables and the lagged variable $U S C_{i, j-1}$ to capture the unauthorized subcontracting status of the previous order delivered by the factory. Finally, we fit a hybrid model that combines information on factory type (see Figure 2) with order-level variables. We first classify factories depending on their type in the training data: factories that during the training period did not subcontract at all (they belonged to type A during that time) are predicted to continue being type A and not subcontract during the test period; similarly, factories that subcontracted all their orders during the training period are predicted to subcontract all their orders during the test period. For factories that subcontracted some orders (but not all) during 
the training period we fit a linear model with order-level variables (without lag or factory fixed effects).

After fitting the linear models, we compute the predicted probabilities of unauthorized subcontracting for the orders in the test dataset and apply the following classification rule: if the predicted probability of unauthorized subcontracting of a given order is greater than a threshold $\tau$, we predict it will, indeed, be subcontracted; if it is $\tau$ or smaller, we predict it will not. Figure 3 shows the receiver operating characteristic (ROC) curve for each model, and Table 8 shows the area under each ROC curve, obtained by varying the threshold $\tau$ between 0 and 1 . If we set $\tau=0.5$, which is arguably the most parsimonious choice, we obtain the accuracies shown in Table 9, and the Type I and II errors shown in Table 10.

We use two baseline models as a benchmark. The first one is a random model: for every order in the test data, we predict whether it will be subcontracted by drawing a random number in the discrete set $\{0,1\}$. The second baseline model is to predict every order to have the most likely outcome (to not be subcontracted). The realized ROC curves, AUC, accuracies, and type I and II errors of these models are also shown in Figure 3 and Tables 8-10. Note that the accuracy of these models differs from the theoretical one ( 0.5 and 0.64 , respectively) due to seasonality in the data. For instance, in the $80 \%-20 \%$ split, unauthorized subcontracting is almost $50 \%$ during the test period, so for this split the naive baseline model $(U S C=0)$ will have a large number of false negatives. Note also that the two baseline models have the same ROC curve (their FPR and TPR is the same for all thresholds, given a split).

\begin{tabular}{lcccc}
\hline Training-test & $20 \%-80 \%$ & $40 \%-60 \%$ & $60 \%-40 \%$ & $80 \%-20 \%$ \\
\hline Baseline (two models) & 0.5 & 0.5 & 0.5 & 0.5 \\
Order variables & 0.691 & 0.6403 & 0.5874 & 0.5663 \\
Order + factory FE & 0.9124 & 0.9108 & 0.9052 & 0.8912 \\
Order + lagged USC & 0.9442 & 0.9328 & 0.9254 & 0.9265 \\
Order + factory type & 0.9079 & 0.8857 & 0.886 & 0.8113 \\
\hline
\end{tabular}

Table 8 Area under the ROC curve of the linear prediction at the order level.

\begin{tabular}{lcccc}
\hline Training-test & $20 \%-80 \%$ & $40 \%-60 \%$ & $60 \%-40 \%$ & $80 \%-20 \%$ \\
\hline Baseline (random) & 0.5018 & 0.4983 & 0.4974 & 0.4944 \\
Baseline (USC=0) & 0.6233 & 0.606 & 0.5685 & 0.4786 \\
Order variables & 0.6673 & 0.6371 & 0.5797 & 0.5117 \\
Order + factory FE & 0.8387 & 0.8512 & 0.8502 & 0.8246 \\
Order + lagged USC & 0.9359 & 0.9266 & 0.9205 & 0.92 \\
Order + factory type & 0.7983 & 0.784 & 0.805 & 0.6786 \\
\hline
\end{tabular}

Table 9 Accuracy of the linear prediction at the order level. 

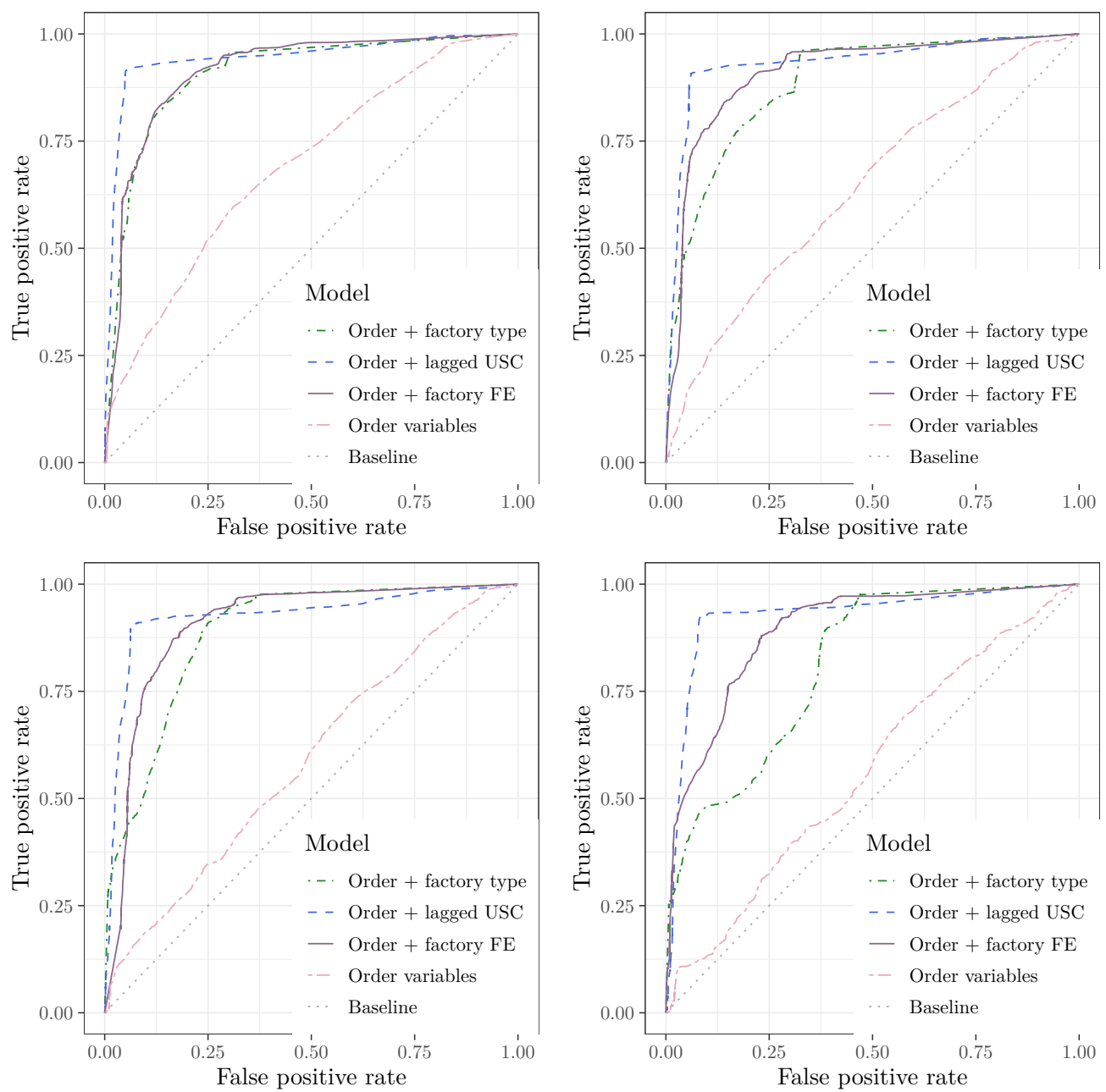

Figure 3 ROC curve of the linear prediction for our four different models (order variables, order variables + factory FE, order variables + lagged unauthorized subcontracting, order variables + factory type), using $20 \%$ of the data for training and $80 \%$ for test (upper left), $40 \%-60 \%$ (upper right), $60 \%-40 \%$ (bottom left), and $80 \%-20 \%$ (bottom right).

As we can see in Tables 8-10, including a factory fixed effect improves all metrics significantly; in particular, the accuracy of the prediction is greater than 0.82 . Hence, the middleman can correctly predict whether or not unauthorized subcontracting will occur for more than $82 \%$ of the orders, and can do so using information at his disposal. If it were possible to observe the factory's decision for every order it produced, then by adding a lagged dependent variable it would be possible to predict unauthorized subcontracting with more than $92 \%$ accuracy. However, knowing every factory decision might not be realistic. Using only order-level variables, without fixed effects, leads to a lower accuracy (51-66\%) due to the number of false negatives: of all the orders that were subcontracted, the model is able to predict only 20-30\% of them (see Table 10). If the only information that is known about a supplier's past is its type, then our model's accuracy is around 79\%, except 
Caro, Lane, and Sáez de Tejada Cuenca: Can Brands Claim Ignorance?

\begin{tabular}{llcccc}
\hline Training-test & & $20 \%-80 \%$ & $40 \%-60 \%$ & $60 \%-40 \%$ & $80 \%-20 \%$ \\
\hline Baseline (random) & Type I & 0.4999 & 0.5066 & 0.5017 & 0.504 \\
& Type II & 0.4954 & 0.4941 & 0.5038 & 0.507 \\
Baseline (USC=0) & Type I & 0 & 0 & 0 & 0 \\
& Type II & 1 & 1 & 1 & 1 \\
Order variables & Type I & 0.0537 & 0.1572 & 0.18 & 0.176 \\
& Type II & 0.7943 & 0.6792 & 0.7368 & 0.7749 \\
Order + factory FE & Type I & 0.0791 & 0.108 & 0.1639 & 0.2804 \\
& Type II & 0.2973 & 0.2116 & 0.1314 & 0.079 \\
Order + lagged USC & Type I & 0.0517 & 0.061 & 0.0687 & 0.0828 \\
\multirow{2}{*}{ Order + factory type } & Type II & 0.0846 & 0.0924 & 0.0939 & 0.0775 \\
& Type I & 0.1021 & 0.1487 & 0.1983 & 0.2836 \\
& Type II & 0.3567 & 0.3149 & 0.1905 & 0.3561 \\
\hline
\end{tabular}

Table 10 Type I and II errors of the linear prediction at the order level.

for the $80 \%-20 \%$ split, in which it decreases to $67 \%$. If we look at this model's ROC curve and the area underneath, they are fairly similar to those of the linear model with factory fixed effects when the training dataset is small but, as its size increases (more precise information about factories' past becomes available), these two models' metrics become increasingly different.

One caveat of the prediction models presented here is that they are highly affected by seasonality patterns in unauthorized subcontracting, which are driven by the peaks of workload in different times of the year. This makes the accuracy of the prediction actually decrease when the size of the training dataset increases. Unfortunately, we only have eight months of data, which means that we cannot include any seasonality variable in our prediction. However, this issue would be solved if more data became available. An additional cause for the decrease in accuracy when the training dataset is larger is overfitting: the accuracy ratio between training and test is increasing in the size of the training dataset. A full implementation would have to take care of these details but the starting point provided here is already quite promising. Note that this prediction model relies on factories' past data. In the e-companion, we propose a model to predict whether a supplier will engage in unauthorized subcontracting when there is no information about its past behavior.

\section{Discussion and Managerial Insights}

Unauthorized subcontracting in the apparel industry is a problem that needs attention. Most disclosed severe violations of labor standards and industrial catastrophes occur in second tier suppliers that retailers have not authorized. In this paper, we have shown that this problem can be addressed, as it is predictable and related to some operational variables that buyers can act on.

We proposed two research questions. As the main drivers of unauthorized subcontracting, we first observe a great amount of autocorrelation between orders at the same factory. An order is $87 \%$ more likely to be subcontracted without authorization if the previous order by the same factory was also subcontracted. Price pressure is another driver of unauthorized subcontracting: an order 
with a unit price $10 \%$ lower than the factory's average for that product category, which happens for one in every three orders in our data, is $4 \%$ more likely to be subcontracted, and an order with a price pressure of $25 \%$, which happens $12 \%$ of the times, is $9 \%$ more likely to be subcontracted without the buyer's authorization. Every additional day in an order's lead time is associated with an increase of $0.2 \%$ in its probability of being subcontracted, which suggests that basic productswhich have longer lead times - are more likely to be subcontracted than fashion products. Orders produced for a buyer that is a major brand are $22 \%$ less likely to be subcontracted. We find no individual effect of factory specialization on the probability of unauthorized subcontracting.

The results in this paper show that buyers should study suppliers' past unauthorized subcontracting behavior before starting to work with them but also that they could minimize the probability of each individual order being subcontracted by not exerting price pressure and by monitoring suppliers' workload closely to avoid overutilization. Knowing that factories suffer from poor production planning (Hurst et al. 2005), buyers should collaborate with their suppliers and offer training and consulting to help them organize their production efficiently, as well as develop the technical capabilities that each product type requires (Locke et al. 2007, Bloom et al. 2013, Kraft et al. 2020). On a larger scale, similar to Caro et al. (2018), there is an opportunity for buyer consortiums that jointly monitor their suppliers to avoid overutilization. In the case of intermediaries, they can also work closely with brands to help them plan their orders, taking into account the workload upstream in the supply chain. This approach seems more plausible for basic apparel. For fashion products, buyers can try to emulate the strategy followed by the Spanish retailer Zara, which consists in operating reasonably below capacity on average to ensure rapid response times (Caro 2012). Of course, these operational measures are complements, not substitutes, of regulations on purchasing practices from brands (Anner et al. 2013, M. Taplin 2014), pressure from consumers and society (M. Taplin 2014, Toffel et al. 2015, Thorlakson et al. 2018), and laws on working conditions and supplier practices, which may work even under limited enforcement (Bastani and de Zegher 2019).

For our second research question, we have proposed a simple prediction method to detect which orders will be subcontracted. The data is split between a training set, that is used to estimate the model's parameters, and a test set. By knowing the fraction of orders that the factory subcontracted during the training period, plus each order's specific characteristics, we can predict unauthorized subcontracting with more than $82 \%$ accuracy. Therefore, for at least 4 out of 5 orders, unauthorized subcontracting could have been predicted correctly and better sourcing decisions could have been made to prevent it. If unauthorized subcontracting information for the most recent order is available, then one can predict unauthorized subcontracting correctly in more than $90 \%$ of cases. At the supplier level, we can predict accurately whether a supplier will engage in unauthorized subcontracting between $63 \%$ and $80 \%$ of the times, without knowing anything about its 
Caro, Lane, and Sáez de Tejada Cuenca: Can Brands Claim Ignorance?

Article submitted to Management Science; manuscript no. MS-16-02459.R2

past unauthorized subcontracting behavior, only its observable characteristics. This prediction can help buyers select new suppliers.

The data used in this work consists of variables that buyers (retailers or intermediaries) have already at their disposal. Therefore, our findings could be implemented in a decision support system (DSS) to help buyers prevent unauthorized subcontracting among their suppliers. Such system could be used to monitor each factory's workload and queue of pending orders, in addition to tracking the product categories that the factory can produce together with the average price per category. Then, the system could detect and flag orders with a high chance of being subcontracted before they are placed to a given factory. The DSS could also suggest alternative factories that would be more suitable for that order, or could require the user to justify their choice. There is ample literature on how to design systems to nudge users in a desirable direction (Meeker et al. 2016). We must note that our methods rely on time-varying variables. Hence, the DSS would have to update the data and estimations on a rolling horizon basis, which could pose some challenges if the DSS's recommendations induce suppliers to hide information, similar to the backfiring situation described in Plambeck and Taylor (2016).

In addition to detecting risky orders and helping their current suppliers improve their efficiency, buyers should streamline the compliance certification process for factories to be included in the authorized list. This is an approach that some retailers are starting to adopt. Subcontracting is a regular practice in the industry and it only poses a problem when the buyer loses visibility and an order ends up in a non-compliant factory. It is possible that some of the subcontractors have reasonable working conditions but lack a formal compliance qualification because the certification process is too cumbersome. In addition, the buyer might want to learn more about the network of informal factories to add as many as possible to the list of approved suppliers.

As with any empirical study, this paper is subject to some limitations. First, the data is observational and the identification strategy relies on an IV approach to mitigate endogeneity concerns. Second, the main effect we identify is state dependence but the data does not allows us to pinpoint the underlying driver. A preliminary study (available from the authors) suggests that the state dependence effect increases when factory utilization is higher but more research is needed to understand better why state dependence happens and how it manifests itself.

Our work provides opportunities for further research. On the empirical side, it would be important to see other studies that complement ours. For instance, our study is limited to the orders handled by the middleman M. Hence, we do not observe any other orders produced by the factories. Similarly, we are not aware of the sourcing portfolio of the different buyers. With more factory and buyer information and a proper costing model one could look at margins and its interactions, and 
study how they might relate to unauthorized subcontracting. Moreover, there are many open questions on unauthorized subcontracting that our study is not able to answer, e.g., do ISO standards or other codes of conduct make a difference? Or, does the presence of competing factories in the same area make unauthorized subcontracting more/less likely? There is also room for improvement in the prediction of unauthorized subcontracting given the wide range of deep learning techniques that are becoming available. Note as well that our model predicts unauthorized subcontracting, whereas ideally one would want to predict noncompliance, or even better, the chance of a disaster. On the theoretical side, a crucial issue is finding mechanisms to ensure truthful disclosure of unauthorized subcontracting without compromising the option of weeding out the factories that specialize in subcontracting a high percentage of their orders. Another interesting problem is how to assign orders to suppliers with the objective of minimizing cost or time subject to a chance constraint on unauthorized subcontracting. Finally, more research is needed on how to engage brands and consumers in solving the problem of unauthorized subcontracting.

\section{Acknowledgments}

First and foremost we thank the middleman M. for providing the data and for useful discussions that informed the problem. We also thank the participants at the Supply Chain Thought Leaders Roundtable held at the University of Cincinnati and seminar participants at Wharton, Penn State, ASU University of Utah, UNC Chapel-Hill, UW-Madison, and the University of Calgary, for feedback on a preliminary version of this paper. Finally, we thank the Associate Editor and two anonymous referees for their comments that helped strengthen the paper.

\section{References}

Abernathy FH, Dunlop JT, Hammond JH, Weil D (1999) A Stitch in Time: Lean Retailing and the Transformation of Manufacturing-Lessons from the Apparel and Textile Industries (Oxford University Press, USA).

Agrawal V, Lee D (2019) The effect of sourcing policies on suppliers? sustainable practices. Production and Operations Management 28(4):767-787.

Alan Y, Lapré MA (2018) Investigating operational predictors of future financial distress in the US airline industry. Production and Operations Management 27(4):734-755.

Anas A (2019) New bangladesh guidelines on garment subcontracting. Just-Style July 19 online.

Anner M (2018) Binding power: The sourcing squeeze, workers rights, and building safety in bangladesh since rana plaza. Penn State University, Center for Global Workers' Rights (CGWR) 22.

Anner M (2019) Squeezing workers' rights in global supply chains: purchasing practices in the bangladesh garment export sector in comparative perspective. Review of International Political Economy 1-28. 
Anner M, Bair J, Blasi J (2013) Toward joint liability in global supply chains: Addressing the root causes of labor violations in international subcontracting networks. Comp. Lab. L. EJ Pol'y J. 35:1.

Ashida M, Plinke E (2004) Made in China: Is this a sustainable label? Risks and opportunities of the China boom from a socially responsible investment perspective. Technical report, Association for Sustainable and Responsible Investment in Asia.

Babich V, Tang CS (2012) Managing opportunistic supplier product adulteration: Deferred payments, inspection, and combined mechanisms. Manufacturing Service Oper. Management 14(2):301-314.

Barrientos S, Smith S (2007) Do workers benefit from ethical trade? assessing codes of labour practice in global production systems. Third world quarterly 28(4):713-729.

Bastani H, de Zegher JF (2019) Do policies with limited enforcement reduce harm? evidence from transshipment bans. Available at SSRN 3312963 .

Baum C, Schaffer M, Stillman S (2015) Ivreg29: Stata module for extended instrumental variables/2sls and gmm estimation (v9) .

Bloom N, Eifert B, Mahajan A, McKenzie D, Roberts J (2013) Does management matter? evidence from india. The Quarterly Journal of Economics 128(1):1-51.

Butler S (2014) Primark to pay $£ 6 m$ more to victims of Rana Plaza factory in Bangladesh. The Guardian March 16.

Buzacott JA, Shanthikumar JG (1993) Stochastic models of manufacturing systems, volume 4 (Prentice Hall Englewood Cliffs, NJ).

Cameron AC, Trivedi PK (2005) Microeconometrics: methods and applications (Cambridge university press).

Cameron AC, Trivedi PK (2010) Microeconometrics using Stata (Stata press College Station, TX).

Caro F (2012) Zara: Staying fast and fresh. Technical report, The Case Center. Reference number 612-006-1.

Caro F, Chintapalli P, Rajaram K, Tang CS (2018) Improving supplier compliance through joint and shared audits with collective penalty. Manufacturing \& Service Operations Management 20(2):363-380.

Caro F, Martínez-de-Albéniz V (2015) Fast fashion: Business model overview and research opportunities. Retail supply chain management, 237-264 (Springer).

Chen L, Lee HL (2016) Sourcing under supplier responsibility risk: The effects of certification, audit, and contingency payment. Management Science 63(9):2795-2812.

Cheng TE, Gupta JN, Wang G (2000) A review of flowshop scheduling research with setup times. Production and operations management 9(3):262-282.

Clifford S, Greenhouse S (2013) Fast and flawed inspections of factories abroad. The New York Times September 1.

Cushing BE, Ahlawat SS (1996) Mitigation of recency bias in audit judgment: The effect of documentation. Auditing 15(2):110. 
Delmas M, Montiel I (2009) Greening the supply chain: When is customer pressure effective? Journal of Economics \& Management Strategy 18(1):171-201.

Distelhorst G, Hainmueller J, Locke RM (2016) Does lean improve labor standards? management and social performance in the nike supply chain. Management Science 63(3):707-728.

Donaldson T (2015) Ethical sourcing forum: Subcontracting more prevalent than brands believe. The Sourcing Journal March 27 online.

Donaldson T (2017) Cambodia faces alarming threat of garment sector subcontracting. The Sourcing Journal May 30 online.

Drennan J (2015) Laundering the global garment industry's dirty business. Foreign Policy April 24 online.

Dyer JH (1996) Specialized supplier networks as a source of competitive advantage: Evidence from the auto industry. Strategic management journal 271-291.

Erev I, Haruvy E (2013) Learning and the economics of small decisions. The handbook of experimental economics 2:9781400883172-011.

Goodman P (2013) Bangladesh tragedy proves global garment trade too big to supervise. Huffington Post May 9.

Greene WH (2003) Econometric analysis (Pearson Education India).

Greenhouse S (2013) Europeans fault American safey effort in Bangladesh. The New York Times Nov 18.

Guo R, Lee H, Swinney R (2016) Responsible sourcing in supply chains. Management Science 62(9):27222744 .

Heckman J (1981) Heterogeneity and state dependence. Rosen S, ed., Studies in Labor Markets (Univeristy of Chicago Press).

H\&M (2010) Annual report.

Huang L, Song J, Swinney R (2017) Managing social responsibility in multi-tier supply chains, working paper, available at SSRN 2837332.

Hurst R, Murdoch H, Gould D (2005) Changing over time: Tackling supply chain labour issues through business practice. Technical report, The Impact Overtime Project.

Jiang B (2009) The effects of interorganizational governance on supplier's compliance with SCC: An empirical examination of compliant and non-compliant suppliers. J. Oper. Manag. 27(4):267-280.

Kerppola M, Moody R, Zheng L, Liu A (2014) H\&M's global supply chain management sustainability: Factories and fast fashion. Technical report, William Davidson Institute (WDI) at the University of Michigan.

Kim SH (2015) Time to come clean? Disclosure and inspection policies for green production. Operations Research 63(1):1-20. 
Caro, Lane, and Sáez de Tejada Cuenca: Can Brands Claim Ignorance?

Article submitted to Management Science; manuscript no. MS-16-02459.R2

Kraft T, Valdés L, Zheng Y (2020) Motivating supplier social responsibility under incomplete visibility. Manufacturing $\&$ Service Operations Management .

Labowitz S, Baumann-Pauly D (2014) Business as usual is not an option. Technical report, New York University Center for Business and Human Rights.

Labowitz S, Baumann-Pauly D (2015) Beyond the tip of the iceberg: Bangladesh's forgotten apparel workers. Technical report, New York University Center for Business and Human Rights.

Lago A, Martínez-de Albéniz V, Moscoso P, Vall A (2016) The role of quick response in accelerating sales of fashion goods. Analytical Modeling Research in Fashion Business, 51-78 (Springer).

Lee HL, Plambeck E (2009) Ma Jun and IPE: Using information to improve China's environment. Technical report, Stanford Graduate School of Business, Teaching Case SI-115.

Locke R, Amengual M, Mangla A (2009) Virtue out of necessity? Compliance, commitment, and the improvement of labor conditions in global supply chains. Politics $\mathcal{E}$ Society 37(3):319-351.

Locke R, Qin F, Brause A (2007) Does monitoring improve labor standards? Lessons from Nike. Industrial Es Labor Relations Review 61(1):3-31.

M Taplin I (2014) Who is to blame? a re-examination of fast fashion after the 2013 factory disaster in bangladesh. Critical perspectives on international business 10(1/2):72-83.

McKenzie N, Baker R (2016) Surf clothing label Rip Curl using 'slave labour' to manufacture clothes in North Korea. The Sydney Morning Herald February 21 online.

Meeker D, Linder JA, Fox CR, Friedberg MW, Persell SD, Goldstein NJ, Knight TK, Hay JW, Doctor JN (2016) Effect of behavioral interventions on inappropriate antibiotic prescribing among primary care practices: A randomized clinical trial. Journal of the American Medical Association 315:562-570.

Moore B, Hunt T, Ditty S (2016) The fashion transparency index. Technical report, Ethical Consumer and Fashion Revolution.

Nuttall C (2012) Apple agrees to China pollution audit. Financial Times April 2012 online.

Orsdemir A, Hu B, Deshpande V (2019) Ensuring corporate social and environmental responsibility through vertical integration and horizontal sourcing. Manufacturing \& S Service Operations Management 21(2):417-434.

Plambeck E, Taylor T (2016) Supplier evasion of a buyer's audit: Implications for motivating compliance with labor and environmental standards. Manufacturing Service Oper. Management 18(2):184-197.

Porteous A, Rammohan S, Lee H (2015) Carrots or sticks? Improving social and environmental compliance at suppliers through incentives and penalties. Production Oper. Management 24(9):1402-1413.

Robertson H, Heng S (2014) Brands dodge blame over substandard factory. The Cambodian Daily July 22 online. 
Rosa-Hatko W, Gunn EA (1997) Queues with switchover: A review and critique. Annals of Operations Research 69:299-322.

Sarkar S, Sriram RS (2001) Bayesian models for early warning of bank failures. Management Science 47(11):1457-1475.

Smithers R (2015) Rana Plaza disaster: Benetton donates \$1.1m to victims' fund. The Guardian April 17.

Tang CS, Babich V (2014) Using social and economic incentives to discourage Chinese suppliers from product adulteration. Business Horizons 57(4):497-508.

Theuws M (2015) Hidden subcontracting in the garment industry. Technical report, Centre for Research on Multinational Corporations.

Thorlakson T, de Zegher JF, Lambin EF (2018) Companies contribution to sustainability through global supply chains. Proceedings of the National Academy of Sciences 201716695.

Toffel MW, Short J, Ouellet M (2015) Codes in context: How states, markets, and civil society shape adherence to global labor standards. Regulation $\mathcal{E}$ Governance 9(3):205-223.

Vairaktarakis GL (2013) Noncooperative games for subcontracting operations. Manufacturing Service Oper. Management 15(1):148-158.

Van Mieghem J (2008) Operations strategy (Belmont, MA: Dynamic Ideas).

Vaughan-Whitehead D, Pinedo Caro L (2017) Purchasing practices and working conditions in global supply chains: Global survey results. Technical report, International Labour Organization, INWORK Issue Brief No. 10.

Wooldridge JM (2010) Econometric analysis of cross section and panel data (MIT press). 